\title{
The Study of Factors Contributing to Chef Turnover in Hotels in Klang Valley, Malaysia
}

\author{
Rahman Bin Abdullah \\ Faculty of Hotel and Tourism Management, Universiti Teknologi MARA \\ Dungun, 23000, Terengganu, Malaysia \\ Tel: 60-9-840-1913/60-1-9741-6820Ｅ-mail: rahma255@tganu.edu.my \\ Mohd Azuan Mohd Alias \\ Faculty of Hotel and Tourism Management, Universiti Teknologi MARA \\ Dungun, 23000, Terengganu, Malaysia
}

Tel: 60-9-840-1913/60-1-9741-6820 E-mail: rahma255@tganu.edu.my

Harnizam Zahari

Faculty of Hotel and Tourism Management, Universiti Teknologi MARA

Dungun, 23000, Terengganu, Malaysia

Tel: 60-9-840-1913/60-1-9741-6820 E-mail: rahma255@tganu.edu.my

Noraida Abdul Karim

Faculty of Hotel and Tourism Management, Universiti Teknologi MARA

Dungun, 23000, Terengganu, Malaysia

Tel: 60-9-840-1913/60-1-9741-6820Ｅ-mail: rahma255@tganu.edu.my

Siti Noraishah Abdullah

Faculty of Hotel and Tourism Management, Universiti Teknologi MARA

Dungun, 23000, Terengganu, Malaysia

Tel: 60-9-840-1913/60-1-9741-6820 E-mail: rahma255@tganu.edu.my

Assoc Prof Hamdin Salleh

Faculty of Hotel and Tourism Management, Universiti Teknologi MARA

Dungun, 23000, Terengganu, Malaysia

Tel: 60-9-840-1913/60-1-9741-6820 E-mail: rahma255@tganu.edu.my

Mohd Fazli Musa

Faculty of Hotel and Tourism Management, Universiti Teknologi MARA Dungun, 23000, Terengganu, Malaysia

Tel: 60-9-840-1913/60-1-9741-6820 E-mail: rahma255@tganu.edu.my 


\begin{abstract}
Service plays a crucial role in the developed countries, and is a growing economic driver in developing countries. Since it offers more work opportunities than product based commodities, the service sector has been taken seriously for the past 30 years. The tourism industry in Malaysia is in the developing process and the service sector is the key driver towards its growth. The main focus of this study is to look at the hotel industry which is within the tourism industry that faces a major problem of employee turnover. In a much smaller scope; the focus would be on employee turnover in the kitchen department which had not been explored quite significantly. The study would attempt to discover aspects which actually perceived by the employees as important for them to retain employment in the kitchen.
\end{abstract}

Keywords: Chef, Hotel industry, Turnover, Tourism, Hospitality

\title{
1. Introduction
}

Services represent the majority of today's economy, not only in developed countries but also developing countries throughout the world. In most countries, the service sector of the economy is very diverse, comprising a wide array of different industries that sell to individual customers and business customers as well as to government agencies and nonprofit organizations (Lovelock and Wright, 2002).Service industries also account for most of the growth in new jobs (Brayner, 1997). In Malaysia, the tourism industry has been identified as the key driver in the growth of the service sector (Economic Planning Unit, Prime Minister’s Department, Malaysia, http;//www.epu.jpm.my).

However, the growth of the service industry and the tourism industry in Malaysia as a whole had been embittered by the high turnover rate in the hotel industry which plays a major role in the service as well as the tourism industry. Denvir and McMahon (1992), defined labor turnover as "the movement of people in and out of employment within an organization". It can be voluntary or involuntary. Correspondingly, on the basis that people leave an organization for multitude of reasons that may not be management related (Eade, 1993).

Turnover in the hospitality industry has been shown to be unacceptably high (Kennedy and Berger 1994), averaging up to 200 or 300 percent per annum (Woods, 1992, Tanke, 1990, Boella, 1988, Wheelhouse, 1989)., although substantial variations exist between different establishments. It was found that the turnover rates in the hospitality industry were not only high in the developing countries but also for developed countries like USA where employee turnover rates are more than $100 \%$ in restaurants (Hudson 1997, Kotler et al, 1999) and 65\% in lodging industry (Hinkin, 2005). This high rate leads to increased orientation, training and development and recruitment costs. The literature has so far identified factors that impact on turnover rates as orientation and socialization process(Kennedy \& Berger, 1994, Woods, 1992), ad hoc recruitment and selection procedures (Bonn \& Forbringer, 1992, Woods \& Macaulay, 1989, Wagner 1991, Wheelhouse 1989), discrimination at workplace (Antolik, 1993), training and development opportunities(Hogan, 1992, Hiemstra, 1990, Conrade et al, 1994), management styles (Lee Ross, 1993, Boella, 1988, Wheelhouse, 1989, Rowden, 1995, Woods and Macaulay, 1989), organizational commitment (Denvir and McMahon, 1992), competition and organizational culture (Woods and Macaulay, 1989), labor shortage (Debrah, 1994, Woods, 1992), stress and burnout (Vallen, 1993, Woods, 1992, 1992, Hom \& Griffeth,1995), the seasonal nature of the industry(Boella 1988, Denvir and McMahon, 1992, and job satisfaction (Bonn and Forbringer, 1992, Hom and Griffeth, 1995, Wheelhouse, 1995). Findings of turnover rate of employees in many industries have addressed the causes, effects and implications of turnover. Numerous studies found that turnover rate was associated with employees demographic and personal characteristics, overall job satisfaction, organization and work environment, job content and intrinsic motivation, the external labor environment, and employees perceptions of alternative jobs, absenteeism, lateness and job performance (McHatton, M.T Van Dyke T, and Steiner, R, (1997), Pizam, A \& Taylor E (1999), Boles J.S, Ross L.E \& Johnson J.T (1995).

Other studies attempted to find the relationship between intervening variables and retention. For example, research suggested that perceived organizational support strongly influenced job satisfaction and organizational commitment. They also concluded that the intent to quit a job was influenced by both job satisfaction and organizational commitment (Susskind, Borchgrevink, Kacmar \& Bryner (2000). Some studies also recommended retention programmes that could reduce turnover and its effects. These included realistic job previews, job enrichment, workspace characteristics, and socialization practices (Boles et al, 1995). The trade literature is filled with prescribed studies to tackle turnover and reduce retention (Hampton, 2000, Shanahan, 2000, Schreiber, 2000, Baumann, 2000, Hensdill, 2000). It is important to highlight, however, that most of the studies addressed management retention or full time employees. Another study by Milman, 2001, addressed the hourly paid employees of their needs of job satisfaction and organizational commitment, but they did not address the relation of the front line managers and the reason the employees keep on working for that particular establishment. Many turnover studies have focused on other industry causes and effects. To date, however, comprehensive and substantial studies have not been conducted to determine the direct and indirect causes of turnover in the hotel industry, although some hotels have undertaken individual turnover analyses to address this issue (Nankervis, 1991, Debrah, 1994). This could be attributed to the fact that, even though employee turnover has financial consequences, the problem is often ignored because the costs are indirect and hidden (Donnely, cited in Hiemstra, 1990). Furthermore, many hotels may consider it simply part of "doing business" in this industry. In their attempts to find and keep employees, 
many companies use incentives such as pay, benefits, promotion and training. However, these efforts often miss their goal, as some research indicated that the front line manager is the key to attracting and retaining employees (Buckingham and Coffman, 1999). In relation to the literature, many studies pertaining to employee turnover has focused mainly in other industry, and turnover studies undertaken in the hospitality industry by far has focused on the management, service staff, amusement park, hotel staff as a whole, and part time or hourly paid employees. To date, there are no studies that has been undertaken to survey the turnover rates among the kitchen staff or the Chef responsible in the kitchen of many hotels. This study focus on the relationship between the Chef in charge of a kitchen and his/her lower level kitchen staff and the effects it has towards the kitchen staff turnover rates as a whole.

\section{Methodology}

For the purpose of this study, employee turnover was defined as "the number of persons hired within six months to replace those leaving or who dropped out of the workforce”. The research solicited data from 15 different hotels in Klang Valley area in Malaysia. A self administered questionnaire was developed based on previous studies on retention, employee turnover, employee satisfaction. The questions included items pertaining to the employee's demographic features like age, gender, employee's role in the organization, income, duration of work, educational level and the position they are currently holding (10 items). The 2nd section of the questionnaire explores the level of satisfaction from the lower level staff point of view towards their superior. The aspects being assess were whether the staff feel their superior is helping in their training process, does their superior influence their turnover intention, does their superior help in their work progress, does their superior look after his/her subordinates, are they helpful in building a conducive working environment, does their superior play a role in their intention to work longer, does their superior behavior negatively influence their intention to work longer, and does the relationship with their superior possess any influence in their intention to stay in the same workplace longer. All these aspects are being measured based on a 7 point Likert scale. To predict retention, respondents were asked on a question about their likelihood to refer someone to their current place of employment and their likelihood of remaining with their current employer.

\section{Findings}

A total of 400 questionnaires were distributed throughout the 15 participating hotels in Klang

Valley area in Kuala Lumpur. Correspondingly, a total of 320 questionnaires was able to be identified as usable and could be used for further data input. The sample identified were a total of $29.2 \%$ working less than 2 years, $42 \%$ has been working for 2 years but less than 5 years and 15\% working for 5 years but less than 10 years. The majority of the respondents are between the age of 21 to 44 (61.3\%) and 35 to 44 years old (27.8\%). 86.5\% of the sample are males and the rest are females. The respondents are divided by executive/sous/executive sous Chef (15.6\%), Chef De Partie (14.1\%), Demi Chef (14.4\%), Commis I, II and III (49.1\%), Cook (4.7\%), and kitchen helper (2.2\%). In terms of income, most respondents' earnings are less than RM10 000 annually (62.5\%). Subsequently, the respondents comes from Coffeehouse Kitchen (25.6\%), Malay \& Banquet Kitchen (20.3\% each respectively), pastry kitchen (10.6\%), Bakery kitchen (9\%), followed by Specialty kitchen ( 6.3\%) others (6.6\%), Garde Manger (5.3\%), Butchery (3.8\%), and Oriental kitchen (0.3\%).

\section{Results}

The results show that the staff perceived their superior (Chef De Partie, Sous Chef and Executive Chef) as an independent person who is able to work with others. They are also very professional in terms of work and significantly helps in their colleagues training process. At the same time, they are also perceived as very helpful and they really look out for their subordinates in terms of work. However, the Chef does not possess significant influence in building a conducive working environment. , although they have no discrimination or anything negative towards their colleagues. The findings, indicate that relationship with one's superior plays a vital role in determining whether a staff will keeps on working in that particular organization. Income is another factor that seems to have a significant role in influencing the staff to stay in the organization. Education also seems to have a strong influence in turnover, whereby its shows the more educated they are, the longer they will stay in one particular organization. These findings could lead to a possibility that the more educated staff received a much better pay compared to the less educated. Another significant findings is that, a person that has been in the industry for more than 2 years but less than 5 years tend to switch organizations much more frequently compared to those that are in the industry for less than 2 years and those that have been working for more than 5 years in the hotel industry. The findings also revealed that the staff holding a position higher than Demi Chef works longer in one organization in comparison with their lower level subordinates.

\section{Discussions}

The findings in the study show 3 main aspects that are quite significant in the kitchen employee's frequency of turnover. The study shows that relationships between the employees and their superior, their income in comparison with their workload, and their level of education play a major role in determining whether they will keep on staying with the organization or move on to a better paying, more satisfying work environment or seek much better opportunities in other 
organization. Another aspect that seems to play a major role in kitchen staff turnover is the time duration they have been in the industry. It seems that the longer they are in the hotel industry, the more committed and loyal they are in their current workplace compared to those that have been in the industry for less than 5 years. Those holding positions of Demi Chef or higher seems to be working longer in their current workplace compared to the lower level kitchen staff. In a study by McGuire, Houser, Jarrar, Moy and Wall 2003, discovered that while money and incentives seem to be an important aspect in retaining employees in their workplace, they also found that job satisfaction does not necessarily come from these two aspects. Instead, they found that respect, recognition, supervisor support, and organization culture seems to be the reason employees stay longer in one particular organization. Some studies specifically addressed recognition by peers and supervisors as key indicators of how employees felt about their jobs (Chinnis et al) (2001), Cronin \& Becherer (1999), Luthans (2000). Luthans (2000) found that "employees place high value on personalized, specific, and instant social rewards such as attention, recognition, and sincere appreciation. Kangas et al (1999) identified a supportive environment as the most important indicator of job satisfaction. In relation to all the previous studies, the findings of this study seems to correlate well with previous study that emphasizes supervisor support, attention, recognition and sincere appreciation which leads to job satisfaction. This particular study found that the relationship between the supervisor and the kitchen staff seems to be an important aspect in decreasing the rate of turnover in the kitchen, thus the findings seem to agree that while monetary benefits seems to be an important aspect in job satisfaction, it certainly is not the only aspect that an organization should look into in decreasing turnover. In another study by Mullins (1995), it was identified that remuneration and performance management is an important aspect of developing Human Resource practices towards retaining employees in the hotel industry. Thus, the findings of this study found that positions they hold which bring in better income can actually be substantiated by the previous study by Mullins (1995).

\section{Conclusions}

The finding of this study that examines employee turnover causes in the context of the kitchen department in the hotel industry seems to correlate with findings from other industries as well. The major findings seem to link other industries into the same route of employee turnover causes. In the kitchen context, the major aspect would be the relationship with the supervisor, which is perceived as very important in gaining job satisfaction. Relationship with the supervisor also means that they are gaining recognition, appreciation and attention from their supervisor. On the other hand, income seems to play a major role in many industries in terms of employee turnover. However, since income and position seems to come hand in hand in the context of the kitchen department, positions could not be denied as an important aspect in retaining employees, thus it is strongly recommended that a clear and attainable route towards promotion of the kitchen staff is developed in order to retain them in the organization which is far better than to select, interview, recruit, train and develop new personnel in the kitchen which could lead to much more work and expenses. On the other hand, since those that have been in the industry for more than 5 years seems to be having a better grip in the organization they are working with, it can only be said that it is due to the fact that they tend to settle or work longer in their current workplace since it is more secure and they don't have the drive to travel more in their career. However, these facts need to be substantiated more in further studies which should be undertaken in order to explore furthermore the hotel industry in Malaysia in general and the kitchen department in specific.

\section{References}

Antolik, C. (1993). Increasing discrimination increasing Turnover. Hotel and Motel Management, 208, (15):20.

Baumann, M.A. (2000). Timeshare resort management; Training the top tool in the battle to keep workers. Hotel \& Motels Management, Vol. 215, No. 7, p.20.

Boella, M.J. (1988). Human Resource Management in the Hotel \& catering Industry. London Hutchinson.

Boles, J.S, Ross, L.E and Johnson J.T. (1995). Reducing employee turnover through the use of pre-employment application demographics. Hospitality Research Journal, Vol. 19, No. 2, pp.19-30.

Bonn, M.A and Forbringer, L.R. (1992). Reducing turnover in the hospitality Industry: An overview of recruitment, selection and retention. International Journal of Hospitality management, 11(1):47-63.

Bryner, R.A. (1997). Hospitality Management, 6th Ed. Iowa: Kendall//Hunt Publishing.

Buckingham, M, and Coffman, C. (1999). First break all the rules. New York, Simon \& Schuster.

Conrade.G, Woods.R., and Ninemier., J. (1994). Training in the U.S Lodging industry: Perception and Reality. Cornell Hotel \& Restaurant Administration Quarterly, 35(5): 16-21.

Debrah, Y.A. (1994). Management of Operative Staff in a labor Scarce Economy; The views of Human Resource managers in the hotel Industry in Singapore. Asia Pacific Journal of Human Resources, 32(1):41-60.

Denvir A, and McMahon, F. (1992). Labor turnover in London Hotels and the cost effectiveness of preventive measures. International Journal of Hospitality Management, 11(2):143-54. 
Economic Planning Unit, Prime Minister’s Department, Malaysia. [Online] Available: http: //www.epu.jpm.my.

Hampton, M. (2000). Motivating and retaining employees. AAHOA Hospitality, Vol. 5, No. 7, pp. 69, 71, 73.

Hensdill, C. (2000). Employee recruitment and retention tactics, Hotels, Vol. 34, No. 3, pp. 29-29.

Hiemstra. S. J. (1990). Employment policies in the lodging industry. International Journal of Hospitality Management, 9(3):207-21.

Hinkin, T.R. (2005). Cornell hotel school's new web based management tool enables lodging companies to evaluate turnover costs. [Online] Available: http://www.hotelschool.cornell.edu/chr/research/centerreports/html (March 1st, 2006).

Hogan.J.J. (1992). Turnover and what to do about it. Cornell Restaurant and Hotel Administration Quarterly, 33(1):40-5.

Hom, P.W and Griffeth. R.W. (1995). Employee turnover. Ohio, South Western Publishing, Ineson, E.M, and Brown, S.H.P. (1992). The use of Biodata for hotel employee selection. International Journal of Contemporary Hospitality Management, 4(2):8-12.

Hudson, R. (1997). A turndown in turnover. Restaurants USA Magazine, April.

Kennedy, D.J \& Berger F. (1994). Newcomer Socialization: Oriented to facts or Feelings? Cornell Hotel \& Restaurant Administration Quarterly, 35(6):58-71.

Kotler, P, Bowen, J. and Makens, J. (1999). Marketing for Hospitality and Tourism, 2nd Edition. New Jersey: Prentice Hall.

Lee Ross, D. (1993). Two styles of manager, two styles of worker. International journal of Contemporary Hospitality Management, 5(4):20-4.

Lovelock, C and Wright L. (2002). Principles of Service marketing in Hospitality, Third Ed, New York, John Wiley \& Sons.

McGuire, M, Houser, J, Jarrar, T, Moy W, Wall M. (2003). Retention. It’s all about respect. Health care Manager, Vol. 22, No. 1, pp 38-44. Lippincott Williams \& Wilkins, Inc.

McHatton, M.T, Van Dyke, T. and Steiner R. (1997). Selection, and retention of managers in the US restaurant sector. International Journal of Contemporary Hospitality Management, Vol. 9, No. 4, p. 155.

Milman, A. (2001). Hourly employee retention in the attraction industry: Research from small and medium sized facilities in Orlando, Florida. Journal of Leisure Property, Vol. 2, No. 1, pp. 40-51.

Nankervis, A.R. (1991). Human resource management in the Australian Hotel Industry. Working Paper no 79, September 1991, faculty of Commerce, University of Western Sydney (Nepean). Sydney.

Pizam, A. and Taylor E, (1999). Absenteeism and turnover in the hospitality industry. In Lee Ross, D. (Ed) HRM in Tourism and Hospitality, London, Cassell.

Rowden, R.W. (1995). The role of human resource development in successful small to mid size manufacturing business: A comparative case study. Human resource development Quarterly, 6(4):355-73.

Schreiber,D.M. (2000). Staying Power: Focus on employee retention. Club Management, Vol. 79, No. 3, pp. 36, 39.

Shanahan, T. (2000). Thinking differently to recruit, hire and reduce turnover. AAHOA Hospitality, Vol. 5, No. 1, pp.89, 91.

Susskind, A.M, Borchgrevink, C. P, Kacmar, K. M. and Bryner R.A. (2000). Customer service employees, behavioral intentions and attitudes;An examination. International Journal of Hospitality Management, Vol. 19, No. 1, pp. 53-77.7

Tanke, M.L. (1990). Human Resource Management for the hospitality Industry. New York. Delmar.

Vallen, G.K. (1993). Organizational climate and burnout. Cornell Hotel and restaurant Administration Quarterly, 36(6): 36-42.

Wagner.G. (1991). Strategies/employee selection makes Ritz Tradition. Lodging Hospitality, 47(7):30.

Wheelhouse, D. (1989). Managing Human Resources in the Hospitality Industry. Michigan: Educational Institute of the American Hotel \& Motel Association.

Woods, R.H and Macaulay. J.F. (1989). Rx for turnover: Retention programmes that work. Cornell Hotel and Restaurant Administration Quarterly, 30(1):78-90.

Woods, R.H. (1992). Managing Hospitality Human Resource. Michigan: Educational Institute of the American Hotel \& Motel Association. 
Correlations

\begin{tabular}{|c|c|c|c|c|c|c|c|c|c|}
\hline & & train & intention & progress & lafter & buildc & rolel & negative & positive \\
\hline \multirow[t]{3}{*}{ train } & Pearson Correlation & 1 & $.150^{\star \star *}$ & -.054 & $.558^{* \star}$ & -.061 & $-.262^{\text {*ᄎ }}$ & $.369^{\star \star *}$ & .000 \\
\hline & Sig. (1-tailed) & . & .004 & .169 & .000 & .139 & .000 & .000 & .496 \\
\hline & $\mathrm{N}$ & 320 & 320 & 320 & 320 & 320 & 320 & 320 & 320 \\
\hline \multirow{2}{*}{ intention } & Sig. (1-tailed) & .004 & & .000 & .000 & .000 & .000 & .000 & .353 \\
\hline & $\mathrm{N}$ & 320 & 320 & 320 & 320 & 320 & 320 & 320 & 320 \\
\hline progress & $\mathrm{N}$ & 320 & 320 & 320 & 320 & 320 & 320 & 320 & 320 \\
\hline \multirow[t]{3}{*}{ lafter } & Pearson Correlation & $.558^{\star \star *}$ & $-.333^{\star \star}$ & .071 & 1 & $-.371^{* *}$ & $-.603^{\star *}$ & $.671^{\text {** }}$ & $.155^{*}$ \\
\hline & Sig. (1-tailed) & .000 & .000 & .102 & . & .000 & .000 & .000 & .003 \\
\hline & $\mathrm{N}$ & 320 & 320 & 320 & 320 & 320 & 320 & 320 & 320 \\
\hline buildc & Pearson Correlation & -.061 & .640 ** & $-.270 * \star$ & $-.371^{\star \star *}$ & 1 & $.727^{\star \star}$ & $-.358^{\star \star *}$ & $-.262^{* 1}$ \\
\hline \multirow{2}{*}{ rolel } & Sig. (1-tailed) & .000 & .000 & .000 & .000 & .000 & . & .000 & .006 \\
\hline & $\mathrm{N}$ & 320 & 320 & 320 & 320 & 320 & 320 & 320 & 320 \\
\hline \multirow[t]{3}{*}{ negative } & Pearson Correlation & $.369 * \star$ & $-.319 * \star$ & $.203^{* *}$ & $.671^{* *}$ & $-.358 * \star$ & $-.483^{\star \star}$ & 1 & $.397^{* *}$ \\
\hline & Sig. (1-tailed) & .000 & .000 & .000 & .000 & .000 & .000 & . & .000 \\
\hline & $\mathrm{N}$ & 320 & 320 & 320 & 320 & 320 & 320 & 320 & 320 \\
\hline \multirow[t]{3}{*}{ positive } & Pearson Correlation & .000 & .021 & .014 & $.155^{\star \star *}$ & $-.262^{* \star}$ & -.139 *ᄎ & $.397^{\star \star *}$ & 1 \\
\hline & Sig. (1-tailed) & .496 & .353 & .403 & .003 & .000 & .006 & .000 & . \\
\hline & $\mathrm{N}$ & 320 & 320 & 320 & 320 & 320 & 320 & 320 & 320 \\
\hline
\end{tabular}

${ }^{\star *}$. Correlation is significant at the 0.01 level (1-tailed). 